\title{
Relationship between physical activity levels and body compositions of university students
}

\author{
Şükran ARIKAN ${ }^{1}$, Serkan REVAN ${ }^{1}$ \\ ${ }^{1}$ Selçuk University, Faculty of Sport Sciences, Konya, Turkey \\ Address Correspondence to Ş, Arıkan, e-mail: sarikan@selcuk.edu.tr
}

\begin{abstract}
The aim of this study is to determine the relationship between physical activity levels and body composition of university students. A total of 155 students (56 women, 99 men) attending Selcuk University Faculty of Sports Sciences voluntarily participated in the research. Body composition was determined by bioelectrical impedance analysis while the International Physical Activity Questionnaire (IPAQ)- short form was used to determine students' physical activity levels. According to the research findings, there was no correlation between body composition variables and physical activity level variables in men ( $p>$ $0,05)$, but there was only a weak but significant negative correlation between total physical activity score and height in women $(\mathrm{p}<0,05, \mathrm{r}=-0.28)$. There was a significant relationship between the total score of high intensity physical activity and body weight $(r=0.21)$, body fat percentage $(r=-0.21)$, lean body mass $(r=0.24)$, basal metabolic rate $(r=0.23)$, body mass index $(r=$ $0.17)$ and waist / hip ratio $(r=0.24)$. Besides it was also determined that there was a significant relationship between total physical activity score and waist / hip ratio $(\mathrm{r}=0.18)$. As a result, it can be said that there is no significant relationship between body composition variables and physical activity level variables of men and women participating in the research.
\end{abstract}

Key words: Physical Activity Level, Body Composition, Bioelectrical Impedance Analysis, International Physical Activity Questionnaire

\section{INTRODUCTION}

Physical activity is defined as any physical movement produced by skeletal muscles and causing exertion of energy (7). There are indisputable evidences regarding the fact that regular physical activity contributes to primary and secondary safeguarding from numerous chronic diseases and reduces the risk of early demise. A linear relation is available between physical activity intensity and health condition and physically more active people have the lowest risk level (29). Today, excessive sedentary behaviors have become the dominant and widespread property of modern life. As the ratios of chronic illnesses and premature deaths increase, the negative impacts of the gradually increasing sedentary life on the public health have become clearer and clearer (2). Sedentary life contains the activities like sleeping, sitting, lying, and watching TV that do not prioritize energy consumption over resting level. Functionally, a sedentary behavior covers the activities containing the 1.0-1.5 metabolic equivalent (MET) energy consumptions (1 MET is the amount of oxygen consumed during a rest and $3,5 \mathrm{ml} / \mathrm{kg} / \mathrm{min}$ ). Light physical activity includes the activities like walking slowly, sitting, writing, cooking, and dishwashing and requires consumption of energy at the level of about 1.6-2.9 MET (19).

Physical activity levels are frequently monitored in order to assess the attitudes of the population toward health and their relation with the health condition that contains fatality and disease ratios. It is necessary to evaluate the physical activity in an accurate manner to determine the effectiveness of the interventions prepared to identify the current levels and alterations in the population and increase the activity levels (21). It was specified that there are many methods used in the determination of physical activity and sedentary behaviors $(8,10,17)$ but there is no golden standard for assessing the validity of the physical activity measurements (9). The short form of the International Physical Activity 
Questionnaire (IPAQ) is a method used frequently in the assessment of physical activity in the largescale epidemiologic studies $(4,20,25)$.

In the studies scrutinizing the relation between physical activity and body composition, it was demonstrated that physical activity maintains or increases the lean tissue mass and affects the body composition positively by supporting the loss of fat $(11,28)$. Identification of the body composition is important in terms of assessing the feedingstate and estimating the potential health risks. The bioelectric impedance analysis (BIA), which is an alternative to the more invasive and expensive methods like Dual energy X-ray absorptiometry, computed tomography, and magnetic resonance imaging, is a valid method used in evaluating body composition (24). The objective of this study is to determine the relation between the physical activity levels and body compositions of university students.

\section{MATERIAL \& METHODS}

Subjects: Total 155 students (56 women, 99 men) between the ages of 18 and 24 studying at the Faculty of Sports Sciences at Selçuk University took part voluntarily in the study. The subjects were informed and their consent forms were caused to be signed by them prior to the study.

Body Weight and Height Measurement: The heights $(\mathrm{cm})$ and body weights $(\mathrm{kg})$ of the subjects were measured using a mechanical weigh (Seca brand) with a meter measuring heights, as bare feet, feet pressing smoothly on the floor, heels adjoined, knees stretched, and body in upright position, with light clothes as much as possible.

Bioelectrical Impedance Analysis: The body compositions of the participants were determined by means of the method of bioelectrical impedance analysis (Bodystat Quadscan 4000). Measurements were taken between 8:00 and 10:00 a.m. in the morning, without the intake of liquids and nutritions following the hunger from the night, in a lying flat position, by placing two electrodes on the

\section{RESULTS}

It was determined that there is a significant difference between the points of body weight, height, body fat percentage, fat mass, fat-free body mass, basal metabolic rate, body mass index, waistto-hip ratio, high-intensity physical activity level, total sitting period, and total physical activity level proximaland distal of the right hand and foot. The participants were asked not to have consumed the food and beverages containing alcohol and caffeine in the 24 hours prior to the test and performed sportive activities. Measurements were postponed in women in line with their menstrual cycle situations.

Physical Activity Assessment Questionnaire: In order to determine the physical activity level of the subjects, the short form of the International Physical Activity Questionnaire (IPAQ) was used. This questionnaire developed to find the physical activity types conducted by individuals during their everyday lives covers the questions in relation with the time spent physically in the last seven days. It questions the frequency of the activities of sports, exercise, and entertainment performed by individuals at home, at work, or when travelling from one place to another. The validity and reliability studies of the questionnaire for Turkey were conducted by Öztürk (18) for university students. Information regarding the time spent in sitting, walking, moderate-intensity physical activity (MIPA), and high-intensity physical activity (HIPA) is obtained. In the evaluation of all the activities, benchmark is the fact that an activity is conducted for at least 10 minutes at once. The minute, day, and MET value (multiples of the oxygen consumption at rest) are multiplied anda score like "METminute/week" is obtained. The physical activity levels are classified a low (<600 MET-minute/week), medium (600-3000 MET-minute/week), and high (>3000 MET-minute/week) (13).

Statistical Analysis: The data were summarized by providing the percentages, averages, and standard deviations. As the data were distributed normally, the independent group $t$ test was used for the pairwise cluster comparisons. In the determination of the relations between the body composition and variables of physical activity level, Pearson Correlation analysis was used. In the study, the level of significance was accepted as 0.0

of the young adult women and men taking part in the study $(\mathrm{p}<0.01)$. In view of the medium intensity physical activity and walking points of the women and men participants, no significant difference was identified $(\mathrm{p}>0.05$; Table 1$)$. 
Table 1. Mean, standard deviation and $\mathrm{t}$ test results of female and male participants

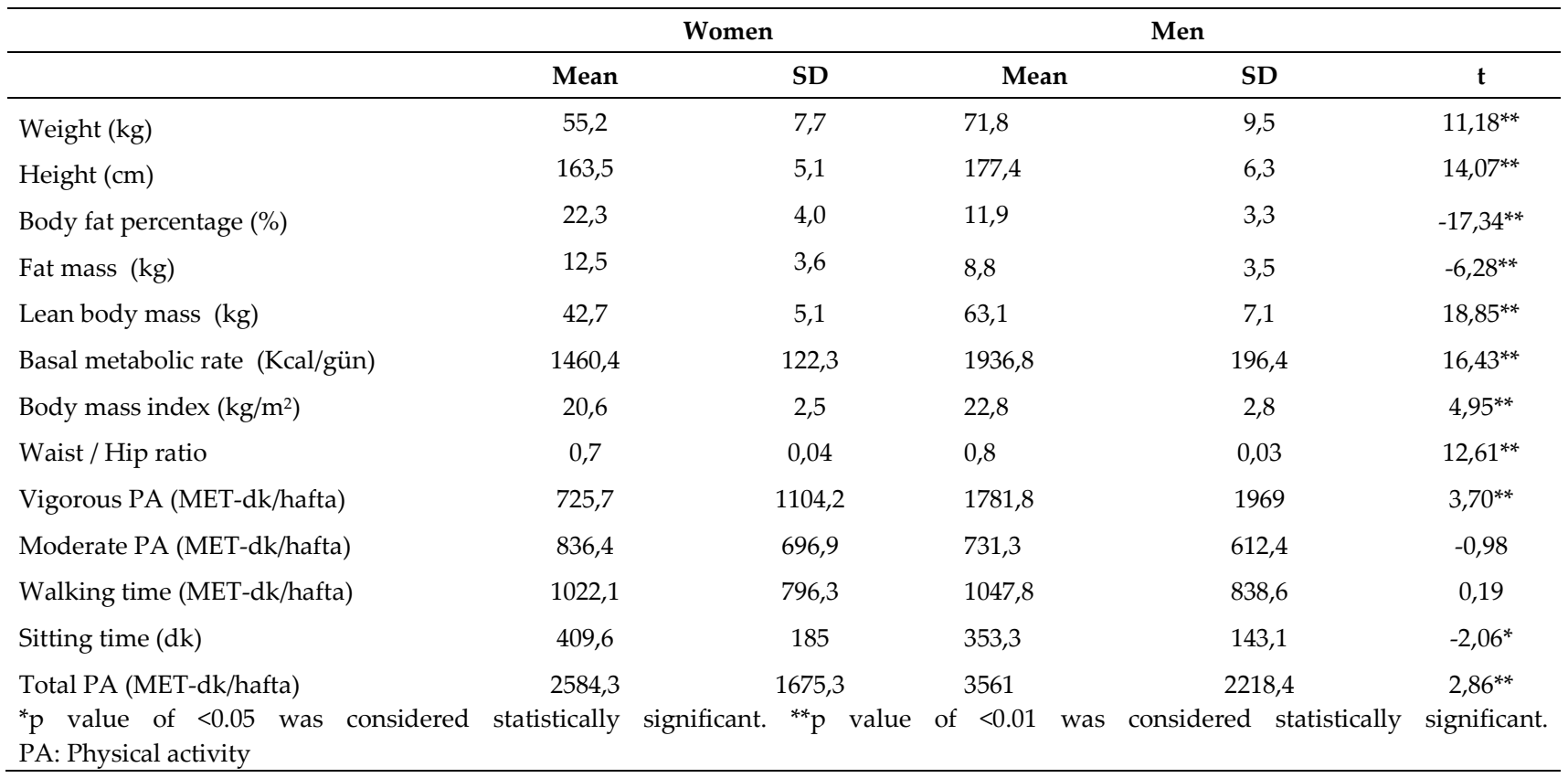

It was determined that $46.45 \%$ of the participants were high, $48.39 \%$ were moderate, and $5.16 \%$ were active at low levels. In terms of the gender, it was determined that majority of the men participants $(53,54 \%)$ were at high activity level, while the majority of the women participants $(58,93 \%)$ were at medium activity level (Table 2).

Table 2. Physical activity levels of participants

\begin{tabular}{|c|c|c|c|c|c|c|}
\hline Activity Levels & Women & & Men & & Total & \\
\hline & $F$ & $\%$ & $F$ & $\%$ & $F$ & $\%$ \\
\hline Low & 4,00 & 7,14 & 4,00 & 4,04 & 8 & 5,16 \\
\hline Medium & 33,00 & 58,93 & 42,00 & 42,42 & 75 & 48,39 \\
\hline High & 19,00 & 33,93 & 53,00 & 53,54 & 72 & 46,45 \\
\hline Total & 56,00 & 100,00 & 99,00 & 100,00 & 155 & 100 \\
\hline
\end{tabular}

A weak but significant level of positive relation between high-intensity physical activity points and the variables of body weight $(r=0.21)$, fat-free body mass $(r=0.24)$, basal metabolic rate $(r=0.23)$, body mass index $(\mathrm{r}=0.17)$, and waist-to-hip ratio $(\mathrm{r}=0.24)$ of the young adults taking part in the study, was determined. Nevertheless, also a weak but statistically significant level of negative relation between the high-intensity physical activity points and body fat percentage $(\mathrm{r}=-0.21)$. As long as the participants' body fat percentages increase, their high-intensity physical activity points decline. In addition, a positive relation between the total physical activity points and waist-to-hip ratio was determined $(\mathrm{r}=0.18)$. When the body composition and physical activity points are scrutinized in terms of gender, no significant relation was found between the body composition variable and physical activity levels, save for the weak significant level of negative relation between height and the total scores of physical activity in women ( $\mathrm{r}=-0.28)$ (Table 3). 
Table 3. The correlation between body composition and physical activity level variables

\begin{tabular}{|c|c|c|c|c|c|c|c|c|}
\hline & Weight & Height & $\begin{array}{c}\text { Body fat } \\
\text { percentage }\end{array}$ & Fat mass & $\begin{array}{c}\text { Lean body } \\
\text { mass }\end{array}$ & $\begin{array}{c}\text { Basal metabolic } \\
\text { rate }\end{array}$ & $\begin{array}{c}\text { Body mass } \\
\text { index }\end{array}$ & $\begin{array}{c}\text { Waist / Hip } \\
\text { ratio }\end{array}$ \\
\hline \multicolumn{9}{|l|}{ Women $(n=56)$} \\
\hline Vigorous PA & $-0,08$ & $-0,19$ & 0,08 & $-0,01$ & $-0,11$ & $-0,11$ & 0,02 & 0,00 \\
\hline Moderate PA & $-0,20$ & $-0,18$ & 0,07 & $-0,08$ & $-0,25$ & $-0,25$ & $-0,14$ & 0,16 \\
\hline Walking time & $-0,03$ & $-0,17$ & 0,21 & 0,10 & $-0,12$ & $-0,12$ & 0,05 & $-0,14$ \\
\hline Sitting time & $-0,06$ & $-0,07$ & $-0,06$ & $-0,04$ & $-0,06$ & $-0,06$ & $-0,03$ & 0,26 \\
\hline Total PA & $-0,15$ & $-0,28^{*}$ & 0,18 & 0,01 & $-0,24$ & $-0,24$ & $-0,02$ & 0,00 \\
\hline \multicolumn{9}{|l|}{ Men $(n=99)$} \\
\hline Vigorous PA & 0,04 & $-0,09$ & 0,02 & 0,03 & 0,04 & 0,03 & 0,10 & 0,09 \\
\hline Moderate PA & $-0,08$ & 0,02 & 0,00 & $-0,04$ & $-0,08$ & $-0,09$ & $-0,10$ & $-0,09$ \\
\hline Walking time & $-0,05$ & $-0,10$ & 0,08 & 0,05 & $-0,10$ & $-0,10$ & $-0,02$ & $-0,01$ \\
\hline Sitting time & $-0,05$ & 0,19 & $-0,17$ & $-0,15$ & 0,00 & 0,00 & $-0,15$ & $-0,15$ \\
\hline Total PA & 0,00 & $-0,12$ & 0,05 & 0,04 & $-0,03$ & $-0,03$ & 0,05 & 0,05 \\
\hline \multicolumn{9}{|l|}{ Total $(n=155)$} \\
\hline Vigorous PA & $0,21^{* *}$ & 0,14 & $-0,21^{* *}$ & $-0,11$ & $0,24^{* *}$ & $0,23^{*}$ & $0,17^{*}$ & $0,24^{* *}$ \\
\hline Moderate PA & $-0,14$ & $-0,09$ & 0,08 & $-0,02$ & $-0,14$ & $-0,14$ & $-0,14$ & $-0,04$ \\
\hline Walking time & $-0,02$ & $-0,07$ & 0,06 & 0,05 & $-0,04$ & $-0,05$ & 0,01 & $-0,03$ \\
\hline Sitting time & $-0,15$ & $-0,06$ & 0,06 & $-0,02$ & $-0,15$ & $-0,14$ & $-0,16$ & $-0,09$ \\
\hline Total PA & 0,12 & 0,07 & $-0,13$ & $-0,08$ & 0,15 & 0,14 & 0,11 & $0,18^{*}$ \\
\hline
\end{tabular}

\section{DISCUSSION \& CONCLUSION}

This study was conducted to determine the relation between the physical activity levels and body compositions of university students. Of the individuals participating in our study, $46,5 \%$ were determined to be active at high level, $48,4 \%$ at moderate level, and 5,2\% at low level. When it comes to gender, it was determined that the majority of the men participants $(53,5 \%)$ are active at high level and the majority of the women participants $(58,9 \%)$ were active at moderate level. In the study conducted by Akova (1), it was reported that $87,4 \%$ of the women and $80 \%$ of the men, and totally $84 \%$ of the individuals, were doing low and moderatelevel physical activity. In a different study performed on university students, the result was that $14,8 \%$ of the students were inactive, $67,5 \%$ were minimally active, and $17,7 \%$ were active (18). In a research carried out in Brazil, 41,1\% of the individuals above the age of 20 were found to be inactive (12). The inactivity levels of the Australian adults were determined as $67,7 \%$ and it was specified that these ratios were $71,2 \%$ in women and $64,8 \%$ in men (6). In a study conducted on the adults living in the US, the inactivity level was reported as $68 \%$ (16). In another study performed in the member states of the European Union, it was stated that both the ratio of the active adults and the level of sedentary lifestyle were $31 \%$ and determined that the frequency of encountering the men who are active at a sufficient level is higher in the women in all the countries (27). In addition, in our study, no significant difference was found between men and women in the medium-intensity physical activity and walking points, while a significant difference was determined between total physical activity, high-intensity physical activity, and sitting points. Total physical activity and high-intensity physical activity points were found higher in men than women and the sitting points of women are higher than those of the men. Savc1 et al. (23) reported that men' total physical activity, moderate and intense level activity points were higher than those of women to a significant extent and no statistically significant difference was determined between the sitting activity points of the men and women university students. In a different study in which healthy young adult university students participated, it was stated that the total points of the men for physical activity, moderate-intensity activity, intense activity, and walking activity were 
higher than those of women significantly (18). When the studies conducted in the world and in our country are examined, it appears that men have higher physical activity level than women. Differently from those studies, the high physical activity levels apparent in both genders in our study make us think that it may be because of the fact that the students participating in our study are the students of the school of sports sciences.

Of the individuals taking part in the study, a significant level of positive relation in terms of highintensity physical activity points and body weight, fat-free body mass, basal metabolic rate, body mass index, and waist-to-hip ratio variables and a significant level of negative relation with the body fat percentage were determined. In addition, a positive relation was found between the total physical activity points and waist-to-hip ratio. When the body composition and physical activity level variables were examined in terms of gender, no significant relation was found between the variables of body composition and physical activity levels, save for the significant level of negative relation between the height and total physical activity points in women. In a study conducted on university students, the fact that the participation of the $51 \%$ of the students in weekly physical activity is at very low level, that their daily sedentary living times are averagely 12 hours, and a significant relation between overweight and sedentary lifestyle is present was determined (22). In a different study, the correlation between some anthropometric measurements and international physical activity questionnaire scores were examined. Accordingly, as the physical activity level increased, the mean values of waist circumference and waist circumference / height of the women and body mass index, neck circumference, waist circumference and waist circumference ratio of the men decreased (1). Kim et al. (15) determined that in the abdominal obesity prevalances and low body weight of the medium and high activity groups had a lower ratio and no significant difference was observed in the groups whose body mass index is above $25 \mathrm{~kg} / \mathrm{m}^{2}$. In consideration of such data, the researchers stated that regular physical activity not only reduces the body weight but also is in relation with a balanced body composition and physical fitness.
Evaluation of sitting period in addition to physical activity and sedentary behaviors is a new and significant field for preventive medicine (4) because sitting period is in an independent relation with fatality ratios. Besides, it suggests that high amounts of sitting cannot be compensated for with occasional leisure time physical activity even if the amount exceeds the current minimum physical activity recommendations (14). In our study, it was determined that there is a significant difference in terms of sitting periods between women (409,6 min) and men (353,3 $\mathrm{min})$ and that sitting periods are not related with the variables of body composition. Differently from our findings from our study, Barlow et al. (3) observed that the high periods of sitting reported in both men and women are significantly related with the prevalence of the high cardiometabolic risk factors including high waist circumference, body fat percentage, as well as obesity. Suliga et al (26) reported that the sitting period of two hours or more a day increases the abdominal obesity risk significantly in the normal, overweight, and obese groups. In a research attended by 9079 individuals from different countries, it was stated that the possibility of being obese by the adults with the sitting periods of eight hours or more a day is $62 \%$ higher than the ones whose period of sitting is less than four hours (5). Such differences in the results of the studies may stem from the difference in the variables of the individuals taking part in the studies, such as age, physical activity level, and body mass index.

There are several limitations of this study. First, the sample size was relatively small, and therefore is likely not representative of university students. Second, study participants were composed of a convenience sample of university students enrolled in faculty of sports science. This may limit the generalizability of the findings to diverse populations. Another limitation of this study is the use of the IPAQ-Sort Form instead of the Long Form version, which is reported to provide more in depth and detailed activity data.

As a result, it can be said that there is no significant relationship between body composition variables and physical activity level of men and women with normal body mass index. 


\section{REFERENCES}

1. Akova İ. 20 yaş üstü erişkinlerde uyku süresi, kalitesi, fiziksel aktivite düzeyi ve bazı antropometrik ölçümler arasındaki ilişkiler. Cumhuriyet Üniversitesi, Tıp Fakültesi, Halk Sağlı̆̆ Anabilim Dalı, Uzmanlık tezi, 2016.

2. Archer E, Blair SN. Physical activity and the prevention of cardiovascular disease: from evolution to epidemiology. Prog Cardiovasc Dis, 2011, 53(6):387-96.

3. Barlow CE, Shuval K, Balasubramanian BA, Kendzor DE , Radford NB, DeFina LF, Gabriel KP. Association between sitting time and cardiometabolic risk factors after adjustment for cardiorespiratory fitness, Cooper Center Longitudinal Study, 2010-2013. Prev Chronic Dis. 2016, 29(13): 181.

4. Bauman A, Ainsworth BE, Sallis JF, Hagströmer M, Craig CL, Bull FC, Pratt M, Venugopal K, Chau J, Sjöström M. The descriptive epidemiology of sitting. A 20-country comparison using the International Physical Activity Questionnaire (IPAQ). Am J Prev Med, 2011,41(2):228-35.

5. Bullock VE, Griffiths P, Sherar LB, Clemes SA. Sitting time and obesity in a sample of adults from Europe and the USA. Ann Hum Biol, 2017,44(3):230-236.

6. Burton NW, Turrell G. Occupation, hours worked and leisure-time physical activity. Prev Med. 2000, 31(6):67381.

7. Caspersen CJ, Powell KE, Christenson GM. Physical activity, exercise and physical fitness: definitions and distinctions for health-related research. Public Health Rep, 1985, 100(2):126131.

8. Craig CL, Marshall AL, Sjöström M, Bauman AE, Booth ML, Ainsworth BE, Pratt M, Ekelund U, Yngve A, Sallis JF, Oja P. International physical activity questionnaire: 12country reliability and validity. Med Sci Sports Exerc, 2003, 35(8):1381-95.

9. Dishman RA, Washburn RA, Schoeller DA. Measurement of Physical Activity, Quest 2012; 53:3, 295-309.

10. Dyrstad SM, Hansen BH, Holme IM, Anderssen SA. Comparison of self-reported versus accelerometermeasured physical activity. Med Sci Sports Exerc, 2014, 46(1):99-106.

11. Fogelholm M, Kukkonen-Harjula K. Does physical activity prevent weight gain--a systematic review. Obes Rev, 2000, 1(2):95-111.

12. Hallal PC, Victora CG, Wells JC, Lima RC. Physical inactivity: prevalence and associated variables in Brazilian adults. Med Sci Sports Exerc, 2003, 35(11):1894-900.

13. IPAQ. Guidelines for data processing and analysis of the International Physical Activity Questionnaire (IPAQ). Short and long forms, 2005. Available from file://C:/Users/asus/Downloads/scoring_protocol\%20(1).pdf

14. Katzmarzyk PT, Church TS, Craig CL, Bouchard C. Sitting time and mortality from all causes, cardiovascular disease, and cancer. Med Sci Sports Exerc, 2009, 41(5):9981005.

15. Kim GS, Im E, Rhee JH. Association of physical activity on body composition, cardiometabolic risk factors, and prevalence of cardiovascular disease in the Korean population (from the fifth Korea national health and nutrition examination survey, 2008-2011). BMC Public Health, 2017, $21 ; 17(1): 275$

16. Martin SB, Morrow JR Jr, Jackson AW, Dunn AL. Variables related to meeting the $\mathrm{CDC} / \mathrm{ACSM}$ physical activity guidelines. Med Sci Sports Exerc, 2000, 32(12):2087-92.

17. Newton RL Jr, Han H, Zderic T, Hamilton MT. The energy expenditure of sedentary behavior:

a whole room calorimeter study. PLoS One, 2013, 3;8(5):63171.

18. Öztürk M. Üniversitede Eğitim Öğretim Gören Öğrencilerde Uluslararası Fiziksel Aktivite Anketinin Gecerliliği ve Güvenirliği ve Fiziksel Aktivite Düzeylerinin Belirlenmesi, Yüksek Lisans Tezi, Hacettepe Universitesi, 2005, Ankara.

19. Pate RR, O'Neill JR, Lobelo F. The evolving definition of "sedentary". Exerc Sport Sci Rev, 2008, 36(4):173-8.

20. Pengpid S, Peltzer K, Kassean HK, Tsala Tsala JP, Sychareun $\mathrm{V}$, Müller-Riemenschneider F. Physical inactivity and associated factors among university students in 23 low-, middle- and high-income countries. Int J Public Health, 2015, 60(5):539-49

21. Prince SA, Adamo KB, Hamel ME, Hardt J, Connor Gorber S, Tremblay M. A comparison of direct versus selfreport measures for assessing physical activity in adults: a systematic review. Int J Behav Nutr Phys Act, 2008; 6;5:56.

22. Rangel Caballero LG, Rojas Sánchez LZ, Gamboa Delgado EM. Overweight and obesity in Colombian college students and its association with physical activity]. Nutr Hosp, 2014, $1 ; 31(2): 629-36$

23. Savcı S, Öztürk M, Arıkan H, Ince İnal D, Tokgözoğlu L. Üniversite öğrencilerinin fiziksel aktivite düzeyleri. Türk Kardiyol Dern Arş, 2006; 34: 166-172.

24. Sergi G, De Rui M, Stubbs B, Veronese N, Manzato E. Measurement of lean body mass using bioelectrical impedance analysis: a consideration of the pros and cons. Aging Clin Exp Res, 2017, 29(4):591-597.

25. Sigmundová D, Sigmund E, Hamřík Z, Kalman M, Pavelka J, Frömel K. Sedentary Behaviour and Physical Activity of Randomised Sample of Czech Adults Aged 20-64 Years: IPAQ and GPAQ Studies between 2002 and 2011. Cent Eur J Public Health, 2015, 23: 91-6.

26. Suliga E, Cieśla E, Rębak D, Kozieł D, Głuszek S. Relationship Between Sitting Time, Physical Activity, and Metabolic Syndrome Among Adults Depending on Body Mass Index (BMI). Med Sci Monit, 2018, 26 (24): 7633-7645.

27. Sjöström M, Oja P, M. Hagströmer M, Smith BJ, Bauman A. Health-enhancing physical activity across European Union 
countries: the Eurobarometer study. J Public Health. 2006, 14: 291-300.

28. Toth MJ, Beckett T, Poehlman ET. Physical activity and the progressive change in body composition with aging: current evidence and research issues. Med Sci Sports Exerc, 1999, 31(11): 590-6.
29. Warburton DE, Nicol CW, Bredin SS. Health benefits of physical activity: the evidence. CMAJ, 2006, $14 ; 174(6): 801-9$ 